Open Access

\title{
A comprehensive evaluation of interaction between genetic variants and use of menopausal hormone therapy on mammographic density
}

Anja Rudolph ${ }^{1 *}$ (D, Peter A. Fasching ${ }^{2,3}$, Sabine Behrens ${ }^{1}$, Ursula Eilber ${ }^{1}$, Manjeet K. Bolla ${ }^{4}$, Qin Wang ${ }^{4}$, Deborah Thompson ${ }^{4}$, Kamila Czene ${ }^{5}$, Judith S. Brand ${ }^{5}$, Jingmei Li ${ }^{5}$, Christopher Scott ${ }^{6}$, V. Shane Pankratz ${ }^{6}$, Kathleen Brandt ${ }^{7}$, Emily Hallberg ${ }^{8}$, Janet E. Olson ${ }^{8}$, Adam Lee ${ }^{9}$, Matthias W. Beckmann², Arif B. Ekici ${ }^{10}$, Lothar Haeberle $^{2}$, Gertraud Maskarinec ${ }^{11}$, Loic Le Marchand ${ }^{11}$, Fredrick Schumacher ${ }^{12}$, Roger L. Milne ${ }^{13,14}$, Julia A. Knight ${ }^{15,16}$, Carmel Apicella ${ }^{14}$, Melissa C. Southey ${ }^{17}$, Miroslav K. Kapuscinski ${ }^{14}$, John L. Hopper ${ }^{14}$, Irene L. Andrulis ${ }^{18,19}$, Graham G. Giles ${ }^{13,14}$, Christopher A. Haiman ${ }^{12}$, Kay-Tee Khaw ${ }^{20}$, Robert Luben²1, Per Hall, Paul D. P. Pharoah ${ }^{4,22}$, Fergus J. Couch ${ }^{23}$, Douglas F. Easton ${ }^{4,22}$, Isabel dos-Santos-Silva ${ }^{24}$, Celine Vachon ${ }^{8}$ and Jenny Chang-Claude ${ }^{1}$

\begin{abstract}
Introduction: Mammographic density is an established breast cancer risk factor with a strong genetic component and can be increased in women using menopausal hormone therapy (MHT). Here, we aimed to identify genetic variants that may modify the association between MHT use and mammographic density.

Methods: The study comprised 6,298 postmenopausal women from the Mayo Mammography Health Study and nine studies included in the Breast Cancer Association Consortium. We selected for evaluation 1327 single nucleotide polymorphisms (SNPs) showing the lowest $P$-values for interaction $\left(P_{\text {int }}\right)$ in a meta-analysis of genome-wide gene-environment interaction studies with MHT use on risk of breast cancer, 2541 SNPs in candidate genes (AKR1C4, CYP1A1-CYP1A2, CYP1B1, ESR2, PPARG, PRL, SULT1A1-SULT1A2 and TNF) and ten SNPS (AREG-rs10034692, PRDM6-rs186749, ESR1-rs12665607, ZNF365-rs10995190, 8p11.23-rs7816345, LSP1-rs3817198, IGF1-rs703556, 12q24-rs1265507, TMEM184B-rs7289126, and SGSM3-rs17001868) associated with mammographic density in genome-wide studies. We used multiple linear regression models adjusted for potential confounders to evaluate interactions between SNPs and current use of MHT on mammographic density.
\end{abstract}

Results: No significant interactions were identified after adjustment for multiple testing. The strongest SNP-MHT interaction (unadjusted $P_{\text {int }}<0.0004$ ) was observed with rs9358531 6.5kb 5' of PRL. Furthermore, three SNPs in PLCG2 that had previously been shown to modify the association of MHT use with breast cancer risk were found to modify also the association of MHT use with mammographic density (unadjusted $P_{\text {int }}<0.002$ ), but solely among cases (unadjusted $P_{\text {int }}$ SNPXMHTxcase-status $<0.02$ ).

Conclusions: The study identified potential interactions on mammographic density between current use of MHT and SNPs near PRL and in PLCG2, which require confirmation. Given the moderate size of the interactions observed, larger studies are needed to identify genetic modifiers of the association of MHT use with mammographic density.

\footnotetext{
* Correspondence: a.rudolph@dkfz.de

'Division of Cancer Epidemiology, German Cancer Research Center (DKFZ),

Im Neuenheimer Feld 581, D-69120 Heidelberg, Germany

Full list of author information is available at the end of the article
}

(C) 2015 Rudolph et al. Open Access This article is distributed under the terms of the Creative Commons Attribution 4.0 International License (http://creativecommons.org/licenses/by/4.0/), which permits unrestricted use, distribution, and reproduction in any medium, provided you give appropriate credit to the original author(s) and the source, provide a link to the Creative Commons license, and indicate if changes were made. The Creative Commons Public Domain Dedication waiver (http://creativecommons.org/publicdomain/zero/1.0/) applies to the data made available in this article, unless otherwise stated. 


\section{Introduction}

High mammographic density for a woman's age and body mass index (BMI) - meaning large radio-dense fibro-glandular areas that appear white or bright on a mammogram - is considered an established risk factor for breast cancer. The association with mammographic density seems to be present for risk of both estrogen receptor negative and estrogen receptor positive breast cancer $[1,2]$. Mammographic density changes over lifetime and generally declines with age [3]. The decline of mammographic density with age may seem paradoxical for a risk factor, as breast cancer risk generally increases with age. This contradiction may be resolved when regarding mammographic density as a risk factor cumulating over time $[4,5]$. Heritable factors have been estimated to explain up to $63 \%$ of variation in mammographic density, implicating a strong genetic component $[6,7]$. Also, recent evidence suggests that the biological attributes leading to greater mammographic density and development of breast cancer have common predisposing genes [8-11].

The use of tamoxifen is associated with a decrease in mammographic density [12-14], whereas the use of menopausal hormone therapy (MHT) is associated with higher mammographic density [15-17]. To date, the biological mechanisms by which MHT use influences mammographic density are largely unknown [18]. On the other hand, it is established that the use of MHT is associated with increased breast cancer risk and that the health risks of extended MHT use may exceed the benefits [19]. However, approximately $5 \%$ of women aged 40 years or older reported current use of oral MHT in the US National Health and Nutrition Examination Survey in 2009-2010 [20]. In Europe, similar proportions of women aged 45-69 years were reported to currently use MHT in 2010 according to estimations based on sales data [21].

To better understand the relationship between MHT use and mammographic density, several studies investigated whether polymorphisms in candidate genes related to hormone metabolism, nuclear hormone receptors and growth factors are associated with mammographic density and whether these polymorphisms show a statistical interaction with MHT use, i.e., modify the association between MHT and mammographic density [22-28]. Most studies did not identify any significant interaction, but the null findings can also be attributed to the generally small sample sizes. Two studies observed potential gene-environment interactions between MHT use and single nucleotide polymorphisms (SNPs) in AKR1C4, CYP1A1-CYP1A2, CYP1B1, ESR2, PPARG, PRL, SULT1A1SULT1A2 and TNF, which warrant confirmation by further studies [24, 28]. We therefore conducted a comprehensive replication analysis in the largest study available to date using genotypes and imputed genotypes of SNPs located in or near these genes.

Candidate gene association studies might have missed gene-environment interactions with genes not selected for study. We previously conducted a meta-analysis of four case-only genome-wide gene-environment interaction studies to identify genetic variants that modify the association of MHT use with breast cancer risk [29]. We hypothesized that these common variants may also modify the association between MHT use and mammographic density. Therefore, we selected the most significant SNPs from the genome-wide $\mathrm{G} \times \mathrm{MHT}$ interaction studies of breast cancer risk for assessment of interaction with MHT use on mammographic density. Furthermore, we included ten variants associated with age-adjusted and BMI-adjusted percent density, dense area or non-dense area at the genome-wide significance level (ZNF365-rs10995190 [30], 12q24-rs1265507 [31], and AREG-rs10034692, PRDM6-rs186749, ESR1-rs12665607, 8p11.23-rs7816345, LSP1-rs3817198, IGF1-rs703556, TMEM184B-rs7289126, and SGSM3-rs17001868 [10]).

\section{Materials and methods \\ Study sample}

The analysis was carried out on pooled data from a nested case-control study of the Mayo mammography health study (MMHS), and from five case-control studies (Australian breast cancer family study (ABCFS), Bavarian breast cancer cases and controls (BBCC), Mayo clinic breast cancer study (MCBCS), Ontario familial breast cancer registry (OFBCR), and the Singapore and Sweden breast cancer study (SASBAC)), two nested case-control studies (Melbourne collaborative cohort study (MCCS) and the Multi-ethnic cohort (MEC)), one cohort study (European prospective investigation into cancer and nutrition (EPIC)) and one family study (Sisters in breast screening study (SIBS)), participating in the Breast Cancer Association Consortium (BCAC) [32]; EPIC and SIBS samples are part of SEARCH [33] within BCAC). Details on study design and recruitment are provided in Additional file 1: Table S1. All participants signed informed consent and the studies were approved by the relevant ethics committees. The names of the individual approving ethics committees for each study can be found within the Acknowledgements section.

Participants were eligible for this study if information on mammographic density, relevant covariates and SNP genotypes was available and if they were of European descent and postmenopausal at the time of mammography. Ancestry informative principal components were used to define probable ethnic ancestry, with the exception of MMHS, where ethnicity was self-reported or abstracted from clinical records. In total, 6,298 individuals were included in the analysis. 


\section{Density measures and exposure definitions}

Each study collected radiographs of mammograms from participants, either in the mediolateral oblique or craniocaudal view. The radiographs were digitized and percent density, dense area, and non-dense area measures were obtained using one of two similar semi-automated methods, Cumulus [34] and Madena [35]. Measurements using the two methods have been found to be highly correlated (Pearson correlation coefficient of 0.86) [36].

Information on relevant exposures such as age, MHT use and BMI was collected individually by each study. The date of the mammogram was the reference date used for all exposure definitions. Ever use of MHT was defined as use of any type of MHT. Women were categorized as current users when using MHT at the date of mammography, former users if they had used MHT previously and never users if they had never used MHT. As part of the DENSNP project [9], individual study data were centrally quality checked and harmonized at the Mayo Clinic, Rochester, Minnesota.

\section{SNP selection, genotyping and imputation}

Using a meta-analysis of four case-only genome-wide gene-environment interaction studies on the association between MHT use, and overall and lobular breast cancer risk [29], 5,000 SNPs were initially selected based on evidence of interaction with MHT. For each SNP, the lower $P$ value for interaction $\left(P_{\text {int }}\right)$ from the results for overall and lobular breast cancer was used. After exclusion of SNPs with minor allele frequency (MAF) $<0.05, P<0.05$ for Cochran's $Q$ or $I^{2} \geq 30 \%$ for study heterogeneity and the availability of the respective SNP data in fewer than two case-only studies, 4,421 SNPs remained. Of these, the 1,391 SNPs showing $P_{\text {int }}<0.003$ were selected for inclusion in a custom Illumina iSelect genotyping array (iCOGS). The iCOGS data were centrally quality controlled after genotyping, which led to the exclusion of 56 SNPs. SNP exclusion criteria were a call rate of $<95 \%$, monomorphism, deviation from Hardy-Weinberg equilibrium with $P<1.0 \times 10^{-7}$ and concordance in duplicate samples <98\% [37]. We additionally excluded seven SNPs with MAF $<0.05$ in our dataset.

We additionally identified 5,457 SNPs located in or $50 \mathrm{~kb}$ around AKR1C4, CYP1A1-CYP1A2, CYP1B1, ESR2, PPARG, PRL, SULT1A1-SULT1A2 and TNF for replication analysis, which were available through iCOGS genotyping and imputation. Of these, 2,541 SNPs were available in BCAC studies and MMHS. For MMHS, the 1000 Genomes Phase I version 3 March 2012 release of the reference panel was used for imputation. Imputation was done using SHAPEIT [38] and IMPUTE.V2 [39]. Imputed SNPs were excluded if the imputation accuracy $r^{2}$ was $<0.3$. For BCAC studies, imputation was conducted centrally in Cambridge, using the same methods and reference panel that were used for MMHS. Imputed SNPs with MAF $<0.05$ or imputation accuracy $r^{2}<0.3$ were excluded from analysis.

In total, we analyzed 1,327 genotyped SNPs selected based on the genome-wide interaction studies, plus 121 genotyped SNPs and 2,420 imputed SNPs located in or near AKR1C4, CYP1A1-CYP1A2, CYP1B1, ESR2, PPARG, PRL, SULT1A1-SULT1A2 and TNF, for replication analysis. In addition, genotypes of AREG-rs10034692, PRDM6-rs186749 (imputed), ESR1-rs12665607, ZNF365rs10995190, 8p11.23-rs7816345, LSP1-rs3817198, IGF1rs703556, 12q24-rs1265507, TMEM184B-rs7289126, and SGSM3-rs17001868 were analyzed.

\section{Statistical analysis}

The mammographic density variables were square-roottransformed to meet the model assumption of normality of the error distribution. Associations between SNPs and mammographic density measures (first, percent density and second, dense area and non-dense area) were assessed using multiple linear regression models (PROC MIXED, SAS 9.2). All models were adjusted for study, age (continuous), case status (breast cancer case/noncase), BMI (continuous), former MHT use (yes/no), number of pregnancies (continuous) and 15 ancestry informative principal components (continuous) that had been constructed previously [40]. For MMHS, the principal components were not available and have been set to 0 . SNP genotypes were coded according to an additive model (0, 1, 2 alleles) and entered as a continuous variable. For imputed SNPs, the estimated allele dosage was entered (values between 0 and 2). To evaluate interactions between SNPs and current MHT use on mammographic density measures, we included a respective interaction term in the models. All statistical tests were two-sided. To account for the number of tests performed, we calculated adjusted $P$ values according to a false discovery rate (FDR) of $10 \%$, applying the method described by Benjamini and Hochberg [41]. We report estimates from analyses pooling individual study data, and assessed between-study heterogeneity by calculating Cochrane's $Q$ and $I^{2}$ based on the per-study estimates, using the package meta, version 2.1-2 within the R software, version 2.15.2.

For illustration, the association between current use of MHT and mammographic density measures stratified by SNP genotypes was calculated. For imputed SNPs, allele dosages $<0.5$ of the coding allele were translated into an imputed homozygous reference genotype. Likewise, allele dosages $\geq 0.5$ and $<1.5$ were translated into an imputed heterozygous genotype and allele dosages $\geq 1.5$ into an imputed homozygous non-reference genotype.

Because SNPs selected for this study were previously found to have a potential multiplicative statistical 
interaction with use of MHT on breast cancer risk, we evaluated whether interactions on mammographic density differed for cases and non-cases by entering a threeway interaction term $(\mathrm{SNP} \times \mathrm{MHT} \times$ case status) into multiple regression models.

Potential functional implications of selected SNPs were assessed using HaploReg v2 [42] and the University of California Santa Cruz (UCSC) genome browser [43]. Linkage disequilibrium (LD) between SNPs of interest was assessed using LD information from the 1000 Genomes Project within HaploReg v2.

\section{Results}

The characteristics of the study population according to mammographic density measurements are described in Table 1. The adjusted mean percent mammographic density was higher in younger women, in women with a lower BMI, and in nulliparous women compared to women with one or more pregnancies. Women currently using MHT compared to never users or former users had a higher adjusted mean percent density as did women diagnosed with breast cancer compared to noncases. Additional file 2: Table S2 shows the characteristics by study.

The beta value from fixed effect meta-analysis of the association between current use of MHT and squareroot-transformed percent density was 0.43 (95\% CI $0.34,0.53)$. There was some indication of between-study heterogeneity $\left(P\right.$ value for heterogeneity $\left.=0.12, I^{2}=35.4 \%\right)$, which was attributable to one study (OFBCR). The beta value for current use of MHT was very similar when analyzing solely cases (beta $=0.42,95 \%$ CI $0.26,0.58$ )

Table 1 Mammographic density measurements by known breast cancer risk factors, mammographic projection, and case status at time of mammography

\begin{tabular}{|c|c|c|c|c|}
\hline Characteristic & Number (\%) & PD, mean $(95 \% C l)^{a, b}$ & Dense area, $\mathrm{cm}^{2}$, mean $(95 \% \mathrm{Cl})^{\mathrm{a}, \mathrm{b}}$ & Non-dense area, $\mathrm{cm}^{2}$, mean $(95 \% \mathrm{Cl})^{\mathrm{a}, \mathrm{b}}$ \\
\hline Total & $6,298(100.0)$ & 18.1 & 28.5 & 143.1 \\
\hline \multicolumn{5}{|l|}{ Age, years } \\
\hline$<50$ & $190(3.0)$ & $25.9(23.8,28.0)$ & $32.9(29.8,36.1)$ & $98.4(92.4,104.5)$ \\
\hline$\geq 50$ to $<60$ & $1,948(30.9)$ & $21.3(20.4,22.2)$ & $30.8(29.4,32.3)$ & $114.9(111.8,118.0)$ \\
\hline$\geq 60$ to $<70$ & $2,939(46.7)$ & $17.6(16.8,18.4)$ & $27.0(25.7,28.3)$ & $127.9(124.7,131.0)$ \\
\hline$\geq 70$ to $<80$ & $1,101(17.5)$ & $16.7(15.7,17.7)$ & $25.8(24.2,27.5)$ & $131.9(128.0,136.0)$ \\
\hline$\geq 80$ & $120(1.9)$ & $14.3(12.3,16.4)$ & $22.1(18.9,25.5)$ & $135.8(126.9,145.0)$ \\
\hline \multicolumn{5}{|l|}{$\mathrm{BMI}, \mathrm{kg} / \mathrm{m}^{2}$} \\
\hline$<25$ & $2,488(39.5)$ & $25.0(24.0,25.9)$ & $30.0(28.7,31.4)$ & $85.9(83.3,88.5)$ \\
\hline$\geq 25$ to $<30$ & $2,244(35.6)$ & $17.6(16.8,18.4)$ & $27.9(26.6,29.3)$ & $129.0(125.7,132.4)$ \\
\hline$\geq 30$ to $<35$ & $1,088(17.3)$ & $13.3(12.4,14.1)$ & $25.5(24.0,27.1)$ & $170.0(165.5,174.6)$ \\
\hline$\geq 35$ & $478(7.6)$ & $10.2(9.3,11.2)$ & $23.0(21.1,24.9)$ & $211.3(204.7,217.9)$ \\
\hline \multicolumn{5}{|l|}{ MHT use } \\
\hline never & $2,885(45.8)$ & $16.2(15.6,16.9)$ & $23.7(22.7,24.8)$ & $128.3(125.6,131.1)$ \\
\hline former & $2,100(33.3)$ & $17.5(16.8,18.3)$ & $26.0(24.8,27.3)$ & $125.7(122.8,128.7)$ \\
\hline current & $1,313(20.9)$ & $19.9(19.0,20.8)$ & $29.7(28.2,31.2)$ & $121.5(118.2,124.9)$ \\
\hline \multicolumn{5}{|l|}{ Parity } \\
\hline nulliparous & $775(12.3)$ & $22.3(21.1,23.5)$ & $32.7(30.9,34.6)$ & $117.5(113.6,121.4)$ \\
\hline 1 full-term pregnancy & $848(13.5)$ & $20.2(19.1,21.3)$ & $31.0(29.2,32.9)$ & $124.0(120.0,128.0)$ \\
\hline 2 full-term pregnancies & $2,369(37.6)$ & $18.3(17.5,19.1)$ & $27.5(26.2,28.9)$ & $126.2(123.1,129.4)$ \\
\hline$\geq 3$ full-term pregnancies & $2,306(36.6)$ & $17.2(16.5,18.0)$ & $25.3(24.0,26.6)$ & $123.2(120.2,126.3)$ \\
\hline \multicolumn{5}{|l|}{ Mammographic view ${ }^{c}$} \\
\hline MLO & $3,454(54.8)$ & $14.6(14.1,15.1)$ & $23.3(22.4,24.2)$ & $139.3(137.1,141.6)$ \\
\hline CC & $2,844(45.2)$ & $19.0(18.5,19.5)$ & $29.0(28.1,30.0)$ & $122.6(120.7,124.6)$ \\
\hline \multicolumn{5}{|l|}{ Case status } \\
\hline non-case & $4,054(64.4)$ & $17.0(16.2,17.8)$ & $25.7(24.5,27.0)$ & $128.4(125.3,131.6)$ \\
\hline case & $2,244(35.6)$ & $20.4(19.6,21.3)$ & $30.0(28.7,31.4)$ & $118.9(116.0,121.8)$ \\
\hline
\end{tabular}

${ }^{\mathrm{a} B a c k-t r a n s f o r m e d}{ }^{\mathrm{b}}$ Adjusted for study, reference age, use of menopausal hormone therapy (MHT), body mass index (BMI) and number of pregnancies. ${ }^{\mathrm{C}}$ In each study mammographs were taken in either the mediolateral oblique $(M L O)$ or craniocaudal $(C C)$ projection. $P D$ percent density 
or non-cases (beta $=0.42,95 \%$ CI $0.30,0.54$ ). The forest plots for the whole study sample, non-cases and cases, respectively are displayed in Fig. 1.

We did not identify significant associations between the analyzed SNPs and percent density (all FDR adjusted $P$ values $>0.1$ ). The top ten SNPs associated with percent

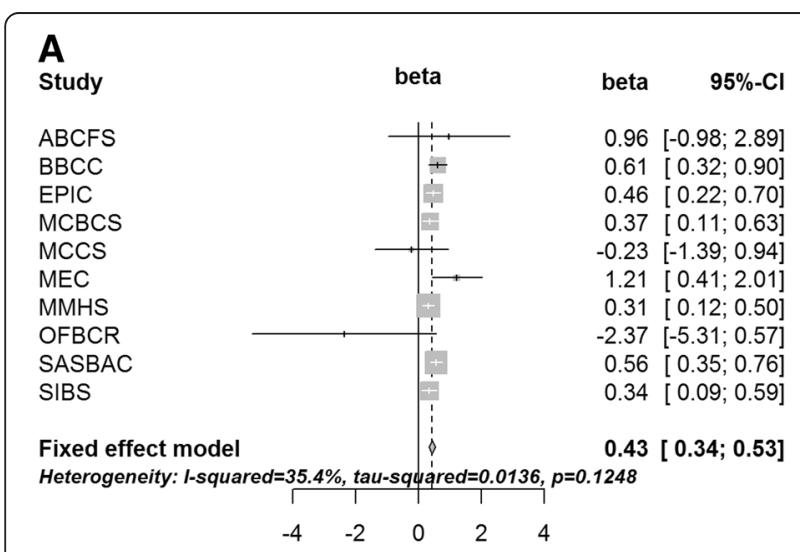

B

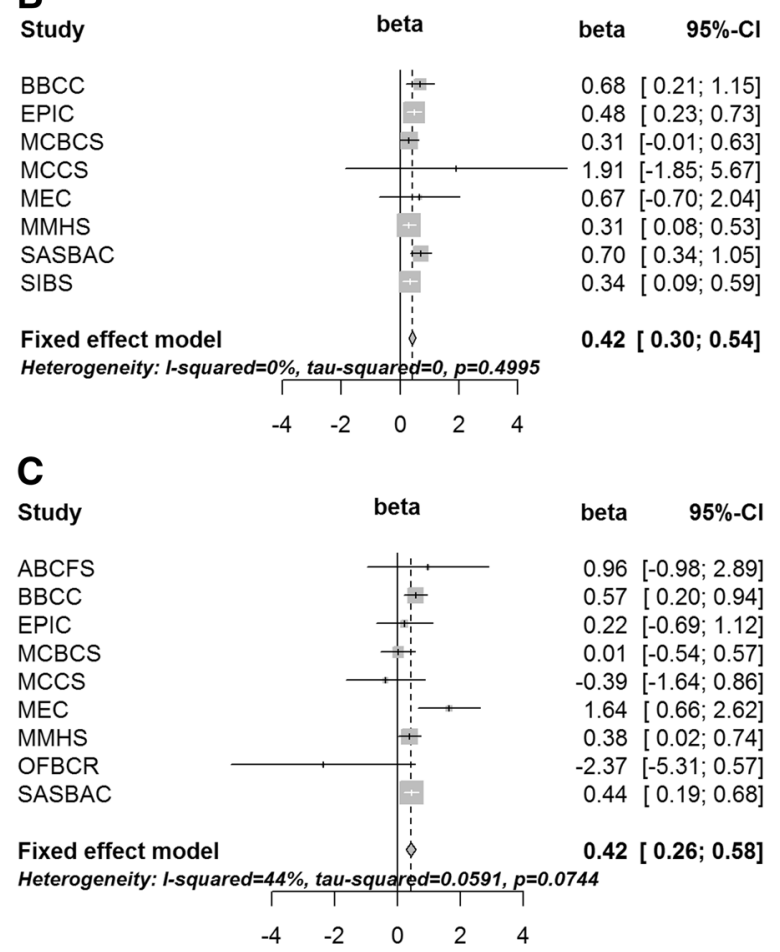

Fig. 1 Meta-analyses of study estimates for association of current use of menopausal hormone therapy with square-root-transformed percent mammographic density analyzing all study subjects (a), non-cases (b) and cases (c). ABCFS Australian breast cancer family study, BBCC Bavarian breast cancer cases and controls, EPIC European prospective investigation into cancer and nutrition, MCBS Mayo clinic breast cancer study, MCCS Melbourne collaborative cohort study, MEC Multi-ethnic cohort, MMHS Mayo mammography health study, OFBCR Ontario familial breast cancer registry, SASBAC Singapore and Sweden breast cancer study, SIBS Sisters in breast screening study density are shown in Table 2. The association with percent density with the lowest $P$ value was observed for rs181042206 on chromosome 15 (5.2kb 3' of CYP1A1, beta $=-0.10,95 \% \mathrm{CI}-0.16,-0.04, P=0.0006)$. The association was not heterogeneous between studies $\left(P\right.$ value for heterogeneity $\left.=0.32, I^{2}=13.6 \%\right)$. For the components of percent density, rs181042206 was more strongly associated with non-dense area (beta $=$ $0.14,95 \%$ CI $0.05,0.23, P=0.002$ ) than dense area (beta $=-0.10,95 \% \mathrm{CI}-0.18,-0.02, P=0.01$ ).

There was no significant interaction between current use of MHT and the SNPs after correcting for multiple testing (all adjusted $P_{\text {int }}>0.1$ ). The ten SNPs showing the lowest $P_{\text {int }}$ on percent mammographic density are displayed in detail in Additional file 3: Table S3. Results for all investigated SNPs can be found in Additional file 4: Tables S6a to S6c. Table 3 shows associations between current MHT use and mammographic density stratified by these SNPs. The imputed variant rs9358531 on chromosome $6\left(6.5 \mathrm{~kb} 5^{\prime}\right.$ of $\left.P R L\right)$ had the strongest interaction $\left(P_{\mathrm{int}}=0.0004\right)$. Current use of MHT was associated with percent mammographic density in women with imputed G/G genotype of rs9358531 with beta = $0.69,95 \%$ CI $0.49,0.89, P=1.4 \times 10^{-11}$. The association was less strong in women with imputed $\mathrm{T} / \mathrm{T}$ genotype (beta $=0.23,95 \%$ CI 0.08, 0.38, $P=2.5 \times 10^{-03}$ ). We did not observe study heterogeneity for this interaction ( $P$ value for heterogeneity $=0.75, I^{2}=0 \%$ ). The interaction between rs9358531 and current use of MHT on percent density was also similar in cases and non-cases (in cases: beta $_{\text {int }}=0.28,95 \%$ CI 0.06, 0.51, $P_{\text {int }}=0.01$; in non-cases: beta $_{\text {int }}=0.21,95 \%$ CI $0.05,0.37, P_{\text {int }}=0.01$; $P_{\text {int }}$ SNP $\times$ MHT $\times$ case status $\left.=0.60\right)$. Six SNPs among the ten SNPs showing the lowest $P_{\text {int }}$ are in LD with rs9358531 (rs9356811, rs10946546, rs9393273, rs12525289, rs12199382, rs12524161) with $r^{2}$ ranging from 0.50 to 0.80 . A genotyped SNP (rs1935007) in moderate LD with rs9356811 $\left(r^{2}=0.42\right)$ had a similar but weaker interaction (beta $_{\text {int }}=0.20,95 \%$ CI 0.07, 0.32, $P_{\text {int }}=0.002$ ) compared to the imputed SNPs in the region. Furthermore, we observed a potential interaction between MHT and a genotyped SNP on chromosome 13 (rs9542456, 505 kb 3' of ATXN8OS). In women carrying the G/G genotype, current use of MHT was associated with percent mammographic density (beta $=0.59,95 \%$ CI $0.46,0.73$, $P=4.7 \times 10^{-18}$ ). This association was attenuated in women carrying the A/A genotype (beta $=0.22,95 \% \mathrm{CI}-0.01$, $\left.0.45, P=0.06, P_{\text {int }}=0.0009\right)$. Also two variants in the proximity of CYP1A1 (rs17861099, rs17861118) had potential interactions, with $P_{\text {int }}=0.001$. Both variants are in high LD with each other $\left(r^{2}=0.83\right)$, but not with the variant rs181042206 identified in the association analysis for percent mammographic density $\left(r^{2}<0.20\right)$. 
Table 2 Ten SNPs with the lowest $P$ values for association with percent mammographic density

\begin{tabular}{|c|c|c|c|c|c|c|c|c|c|c|c|}
\hline \multirow[t]{2}{*}{ SNP } & \multirow[t]{2}{*}{ SNP type } & \multirow[t]{2}{*}{ Chr } & \multirow[t]{2}{*}{ Gene, RefSeq } & \multirow[t]{2}{*}{ Feature } & \multicolumn{2}{|l|}{ Percent density ${ }^{\mathrm{a}}$} & \multirow[b]{2}{*}{$P_{a d j}{ }^{c}$} & \multicolumn{2}{|l|}{ Dense area, $\mathrm{cm}^{2 \mathrm{a}}$} & \multicolumn{2}{|l|}{ Non-dense area, $\mathrm{cm}^{2 \mathrm{a}}$} \\
\hline & & & & & $\operatorname{Beta}^{b}(95 \%$ Cl) & $P$ & & $\operatorname{Beta}^{\mathrm{b}}(95 \% \mathrm{Cl})$ & $P$ & Beta $^{\mathrm{b}}(95 \% \mathrm{Cl})$ & $P$ \\
\hline rs181042206 & Imputed & 15 & $5.2 \mathrm{~kb} 3^{\prime}$ of CYP1A1 & & $-0.10(-0.16,-0.04)$ & 0.0006 & 2.51 & $-0.10(-0.18,-0.02)$ & 0.01 & $0.14(0.05,0.23)$ & 0.002 \\
\hline rs12258125 & Genotyped & 10 & $272 \mathrm{~kb} 5^{\prime}$ of ANKRD30A & & $0.09(0.04,0.14)$ & 0.0008 & 1.53 & $0.10(0.03,0.17)$ & 0.004 & $-0.07(-0.14,0.00)$ & 0.07 \\
\hline rs11616761 & Genotyped & 13 & CDC16 & Intronic & $0.14(0.05,0.23)$ & 0.0022 & 2.83 & $0.18(0.06,0.29)$ & 0.004 & $-0.11(-0.24,0.02)$ & 0.09 \\
\hline rs4632572 & Genotyped & 3 & $254 \mathrm{~kb} 5^{\prime}$ of ALCAM & & $0.08(0.03,0.14)$ & 0.0027 & 2.59 & $0.14(0.07,0.21)$ & 0.0002 & $0.00(-0.08,0.08)$ & 0.96 \\
\hline rs11896627 & Genotyped & 2 & $241 \mathrm{~kb} 5^{\prime}$ of NCKAP5 & & $-0.08(-0.13,-0.03)$ & 0.0032 & 2.49 & $-0.10(-0.17,-0.03)$ & 0.003 & $0.03(-0.05,0.10)$ & 0.51 \\
\hline rs2446585 & Genotyped & 10 & FRMD4A & Intronic & $-0.07(-0.12,-0.02)$ & 0.0038 & 2.46 & $-0.08(-0.15,-0.02)$ & 0.01 & $0.07(-0.01,0.14)$ & 0.07 \\
\hline rs273352 & Genotyped & 18 & MAPRE2 & Intronic & $-0.08(-0.13,-0.02)$ & 0.0058 & 3.22 & $-0.08(-0.15,-0.01)$ & 0.04 & $0.10(0.02,0.18)$ & 0.01 \\
\hline rs477705 & Genotyped & 18 & MAPRE2 & Intronic & $-0.08(-0.13,-0.02)$ & 0.0058 & 2.82 & $-0.08(-0.15,-0.01)$ & 0.03 & $0.10(0.02,0.18)$ & 0.01 \\
\hline rs10776775 & Genotyped & 1 & LOC100287722 & Intronic & $-0.07(-0.12,-0.02)$ & 0.0062 & 2.64 & $-0.09(-0.15,-0.02)$ & 0.009 & $0.01(-0.06,0.08)$ & 0.78 \\
\hline rs2057469 & Genotyped & 9 & RAB14 & $3^{\prime}-$ UTR & $-0.07(-0.12,-0.02)$ & 0.0066 & 2.55 & $-0.08(-0.15,-0.01)$ & 0.02 & $0.08(0.00,0.16)$ & 0.04 \\
\hline
\end{tabular}

${ }^{\mathrm{a}}$ Square-root-transformed. ${ }^{\mathrm{b}}$ Adjusted for study, reference age, case status, current use of menopausal hormone therapy (MHT), former use of MHT, body mass index, number of pregnancies and principal components. 'Adjusted $P$ value, calculated by multiplying $P$ value by number of tests (here $n=3,868$ ) and dividing by assigned rank. SNP single nucleotide polymorphism, Chr chromosome, UTR untranslated region

The ten SNPs showing the lowest $P_{\text {int }}$ for percent mammographic density in this study did not overlap with the 14 SNPs recently identified to be potential modifiers of overall/lobular breast cancer risk associated with MHT use [29]. These 14 previously identified SNPs also did not show clear evidence of interaction with current use of MHT on percent mammographic density when analyzing the whole study sample (Additional file 5: Table S4). However, when testing for threeway interactions between SNP, current MHT use and case status, three SNPs in introns of PLCG2 on chromosome 16 (rs7192724, rs4888190, rs17202296) had differential interaction effects for cases and noncases $\left(P_{\text {int }}\right.$ SNP $\times$ MHT $\times$ case status $=0.005,0.007$, and 0.019, respectively, Additional file 6: Table S5). Potential interactions with current use of MHT on percent density were observed solely for cases $\left(P_{\text {int }}=0.001,0.0004\right.$, 0.001 , respectively), but not in non-cases $\left(P_{\text {int }}=0.57,0.86\right.$, 0.81 , respectively).

In our study sample, the ten variants known from genome-wide association studies (GWASs) were associated with percent mammographic density, dense area or non-dense area as expected, also due to overlap between the discovery samples and the studies included in this work (Additional file 7: Table S7). None of them showed a significant interaction with current use of MHT on percent mammographic density (Additional file 8: Table S8).

\section{Discussion}

We assessed whether 3,878 SNPs selected based on a meta-analysis of four genome-wide case-only geneenvironment interaction studies, candidate gene studies and GWAS of percent mammographic density are differentially associated with mammographic density according to current use of MHT. After accounting for multiple testing, there were no significant interactions for mammographic density between the investigated SNPs and current use of MHT. However, three SNPs in PLCG2 showing potential interaction with MHT use for overall breast cancer risk in our previous study also showed potential interactions with MHT use for mammographic density in this study, but solely among cases. Thus, the results of this study may indicate a potential common pathway between the biological mechanisms underlying higher mammographic density and increased risk of breast cancer associated with MHT use.

The variants rs7192724, rs17202296, and rs4888190 are located within PLCG2, although in two different intronic regions. All three SNPs are located within $6 \mathrm{~kb}$ and are in relatively strong LD ( $\mathrm{D}^{\prime}>0.85, R^{2}>0.71$ ). As none of them are in LD with a coding variant, the effect of the causal SNP may be exerted through a regulatory mechanism. Using HaploReg and the UCSC genome browser, we identified rs12448089 in strong LD with rs4888190 ( $\mathrm{D}^{\prime}=0.98, R^{2}=0.87$ ) as a potential functional variant. SNP rs12448089 is located in a DNase I hypersensitive site and binding motifs of several transcription factors (Additional file 9: Figure S1). Genotypes for rs12448089 were not available in this study.

PLCG2 encodes phospholipase C-gamma 2, an enzyme involved in the transmission of activation signals across the cell membranes predominantly of B cells [44] as well as natural killer cells [45]. PLCG2 plays an important role in immune response regulation [46] and aberrant functioning of PLCG2 due to exon deletions [47] or a missense mutation [46] causes autoimmunity diseases. With regard to breast cancer, PLCG2 has been identified as an irradiation-responsive gene and a potential 
Table 3 Association between mammographic density and current use of menopausal hormone therapy stratified by genotypes of ten SNPs showing the lowest $P$ values for interaction

\begin{tabular}{|c|c|c|c|c|c|c|c|c|c|c|c|}
\hline \multirow[t]{2}{*}{ SNP } & \multirow[t]{2}{*}{ SNP type } & \multirow[t]{2}{*}{ Chr } & \multirow[t]{2}{*}{ Gene } & \multirow{2}{*}{$\begin{array}{l}\text { Density } \\
\text { measure }\end{array}$} & \multicolumn{2}{|c|}{ Homozygous reference genotype $(\mathrm{N})$} & \multicolumn{2}{|c|}{ Heterozygous genotype $(\mathrm{N})$} & \multicolumn{2}{|c|}{ Homozygous non-reference genotype (N) } & \multirow[t]{2}{*}{$P$ interaction } \\
\hline & & & & & $\operatorname{Beta}^{a}(95 \% \mathrm{Cl})$ & $P$ & $\operatorname{Beta}^{\mathrm{a}}(95 \% \mathrm{Cl})$ & $P$ & $\operatorname{Beta}^{a}(95 \% \mathrm{Cl})$ & $P$ & \\
\hline & & & & & $T / T(2000)$ & & T/G (3167) & & G/G (1131) & & \\
\hline \multirow[t]{4}{*}{ rs9358531 } & Imputed & 6 & $6.5 \mathrm{~kb} 5^{\prime}$ of $\mathrm{PRL}$ & PD & $0.23(0.08,0.38)$ & $2.5 \times 10^{-03}$ & $0.46(0.34,0.58)$ & $5.1 \times 10^{-14}$ & $0.69(0.49,0.89)$ & $1.4 \times 10^{-11}$ & 0.0004 \\
\hline & & & & DA & $0.38(0.18,0.58)$ & $2.1 \times 10^{-04}$ & $0.6(0.44,0.76)$ & $1.2 \times 10^{-13}$ & $0.85(0.59,1.12)$ & $2.7 \times 10^{-10}$ & 0.008 \\
\hline & & & & NDA & $-0.17(-0.39,0.05)$ & $1.4 \times 10^{-01}$ & $-0.29(-0.47,-0.12)$ & $1.2 \times 10^{-03}$ & $-0.58(-0.87,-0.29)$ & $1.0 \times 10^{-04}$ & 0.02 \\
\hline & & & & & G/G (2138) & & G/A (3142) & & A/A (1018) & & \\
\hline \multirow[t]{4}{*}{ rs9356811 } & Imputed & 6 & $5.2 \mathrm{~kb} 5^{\prime}$ of $\mathrm{PRL}$ & PD & $0.24(0.1,0.39)$ & $1.1 \times 10^{-03}$ & $0.48(0.36,0.6)$ & $1.3 \times 10^{-14}$ & $0.69(0.48,0.9)$ & $1.5 \times 10^{-10}$ & 0.0004 \\
\hline & & & & DA & $0.39(0.2,0.59)$ & $6.6 \times 10^{-05}$ & $0.6(0.44,0.76)$ & $1.9 \times 10^{-13}$ & $0.89(0.61,1.17)$ & $4.6 \times 10^{-10}$ & 0.005 \\
\hline & & & & NDA & $-0.17(-0.38,0.05)$ & $1.2 \times 10^{-01}$ & $-0.33(-0.51,-0.15)$ & $2.5 \times 10^{-04}$ & $-0.51(-0.82,-0.2)$ & $1.1 \times 10^{-03}$ & 0.05 \\
\hline & & & & & C/C (2158) & & $C / T(3124)$ & & $\mathrm{T} / \mathrm{T}(1016)$ & & \\
\hline \multirow[t]{4}{*}{ rs10946546 } & Imputed & 6 & $17 \mathrm{~kb} 5^{\prime}$ of $\mathrm{PRL}$ & PD & $0.22(0.07,0.37)$ & $3.2 \times 10^{-03}$ & $0.51(0.39,0.63)$ & $2.2 \times 10^{-16}$ & $0.63(0.42,0.84)$ & $3.0 \times 10^{-09}$ & 0.0004 \\
\hline & & & & DA & $0.39(0.19,0.58)$ & $9.0 \times 10^{-05}$ & $0.64(0.48,0.8)$ & $4.8 \times 10^{-15}$ & $0.77(0.49,1.05)$ & $4.9 \times 10^{-08}$ & 0.02 \\
\hline & & & & NDA & $-0.11(-0.32,0.1)$ & $3.1 \times 10^{-01}$ & $-0.37(-0.55,-0.2)$ & $3.4 \times 10^{-05}$ & $-0.49(-0.8,-0.19)$ & $1.5 \times 10^{-03}$ & 0.01 \\
\hline & & & & & $\mathrm{T} / \mathrm{T}(2230)$ & & T/C (3093) & & C/C (975) & & \\
\hline \multirow[t]{4}{*}{ rs9393273 } & Imputed & 6 & $8.1 \mathrm{~kb} 5^{\prime}$ of PRL & PD & $0.24(0.1,0.39)$ & $7.8 \times 10^{-04}$ & $0.49(0.37,0.61)$ & $4.8 \times 10^{-15}$ & $0.68(0.47,0.89)$ & $5.0 \times 10^{-10}$ & 0.0005 \\
\hline & & & & DA & $0.4(0.21,0.59)$ & $3.6 \times 10^{-05}$ & $0.62(0.46,0.78)$ & $8.5 \times 10^{-14}$ & $0.86(0.58,1.15)$ & $2.4 \times 10^{-09}$ & 0.01 \\
\hline & & & & NDA & $-0.16(-0.37,0.05)$ & $1.3 \times 10^{-01}$ & $-0.33(-0.51,-0.16)$ & $2.4 \times 10^{-04}$ & $-0.54(-0.85,-0.23)$ & $6.9 \times 10^{-04}$ & 0.03 \\
\hline & & & & & A/A (2079) & & A/G (3154) & & G/G (1065) & & \\
\hline \multirow[t]{4}{*}{ rs12525289 } & Imputed & 6 & $9.9 \mathrm{~kb} 5^{\prime}$ of $\mathrm{PRL}$ & PD & $0.24(0.09,0.39)$ & $1.5 \times 10^{-03}$ & $0.47(0.35,0.59)$ & $2.0 \times 10^{-14}$ & $0.68(0.47,0.88)$ & $7.8 \times 10^{-11}$ & 0.0005 \\
\hline & & & & DA & $0.4(0.2,0.59)$ & $7.3 \times 10^{-05}$ & $0.59(0.43,0.76)$ & $4.3 \times 10^{-13}$ & $0.88(0.61,1.15)$ & $2.1 \times 10^{-10}$ & 0.009 \\
\hline & & & & NDA & $-0.14(-0.35,0.08)$ & $2.1 \times 10^{-01}$ & $-0.34(-0.51,-0.16)$ & $1.9 \times 10^{-04}$ & $-0.53(-0.82,-0.23)$ & $5.4 \times 10^{-04}$ & 0.03 \\
\hline & & & & & G/G (2090) & & G/A (3142) & & A/A (1066) & & \\
\hline \multirow[t]{4}{*}{ rs12199382 } & Imputed & 6 & $24 \mathrm{~kb} 5^{\prime}$ of PRL & PD & $0.21(0.07,0.36)$ & $4.5 \times 10^{-03}$ & $0.51(0.39,0.63)$ & $1.8 \times 10^{-16}$ & $0.62(0.41,0.82)$ & $2.8 \times 10^{-09}$ & 0.0006 \\
\hline & & & & DA & $0.37(0.17,0.56)$ & $2.5 \times 10^{-04}$ & $0.65(0.49,0.81)$ & $1.7 \times 10^{-15}$ & $0.76(0.49,1.03)$ & $3.5 \times 10^{-08}$ & 0.02 \\
\hline & & & & NDA & $-0.13(-0.35,0.08)$ & $2.2 \times 10^{-01}$ & $-0.35(-0.53,-0.17)$ & $1.1 \times 10^{-04}$ & $-0.49(-0.79,-0.2)$ & $1.1 \times 10^{-03}$ & 0.02 \\
\hline & & & & & G/G (2629) & & G/A (2873) & & A/A (796) & & \\
\hline \multirow[t]{3}{*}{ rs9542456 } & Genotyped & 13 & $505 \mathrm{~kb} 3^{\prime}$ of ATXN8OS & PD & $0.59(0.46,0.73)$ & $4.7 \times 10^{-18}$ & $0.33(0.2,0.45)$ & $4.1 \times 10^{-07}$ & $0.22(-0.01,0.45)$ & $5.9 \times 10^{-02}$ & 0.0009 \\
\hline & & & & DA & $0.75(0.57,0.93)$ & $2.0 \times 10^{-16}$ & $0.45(0.28,0.61)$ & $1.8 \times 10^{-07}$ & $0.44(0.14,0.75)$ & $4.7 \times 10^{-03}$ & 0.02 \\
\hline & & & & NDA & $-0.43(-0.63,-0.24)$ & $1.6 \times 10^{-05}$ & $-0.27(-0.45,-0.08)$ & $4.7 \times 10^{-03}$ & $0.02(-0.32,0.36)$ & $9.2 \times 10^{-01}$ & 0.02 \\
\hline
\end{tabular}


Table 3 Association between mammographic density and current use of menopausal hormone therapy stratified by genotypes of ten SNPs showing the lowest $P$ values for interaction (Continued)

\begin{tabular}{|c|c|c|c|c|c|c|c|c|c|c|c|}
\hline & & & & & $\mathrm{T} / \mathrm{T}(2241)$ & & T/G (3092) & & G/G (965) & & \\
\hline \multirow[t]{4}{*}{ rs12524161 } & Imputed & 6 & $46 \mathrm{~kb} 5^{\prime}$ of PRL & PD & $0.26(0.12,0.41)$ & $2.8 \times 10^{-04}$ & $0.47(0.35,0.6)$ & $3.9 \times 10^{-14}$ & $0.68(0.47,0.89)$ & $4.6 \times 10^{-10}$ & 0.001 \\
\hline & & & & DA & $0.42(0.23,0.61)$ & $1.2 \times 10^{-05}$ & $0.6(0.44,0.76)$ & $4.8 \times 10^{-13}$ & $0.86(0.58,1.14)$ & $2.6 \times 10^{-09}$ & 0.01 \\
\hline & & & & NDA & $-0.14(-0.35,0.06)$ & $1.7 \times 10^{-01}$ & $-0.34(-0.51,-0.16)$ & $2.3 \times 10^{-04}$ & $-0.57(-0.88,-0.26)$ & $3.3 \times 10^{-04}$ & 0.02 \\
\hline & & & & & C/C (5358) & & C/T (899) & & $\mathrm{T} / \mathrm{T}(41)$ & & \\
\hline \multirow[t]{4}{*}{ rs17861099 } & Imputed & 15 & 462 bp 5' of CYP1A1 & $P D$ & $0.48(0.39,0.58)$ & $2.4 \times 10^{-21}$ & $0.09(-0.14,0.32)$ & $4.3 \times 10^{-01}$ & $-0.22(-1.8,1.37)$ & $7.9 \times 10^{-01}$ & 0.001 \\
\hline & & & & DA & $0.65(0.52,0.78)$ & $1.1 \times 10^{-21}$ & $0.13(-0.17,0.43)$ & $3.9 \times 10^{-01}$ & $0.01(-2.09,2.1)$ & $9.9 \times 10^{-01}$ & 0.002 \\
\hline & & & & NDA & $-0.35(-0.5,-0.21)$ & $1.8 \times 10^{-06}$ & $0.02(-0.32,0.35)$ & $9.2 \times 10^{-01}$ & $-0.18(-2.48,2.13)$ & $8.8 \times 10^{-01}$ & 0.04 \\
\hline & & & & & G/G (5337) & & G/A (923) & & A/A (38) & & \\
\hline \multirow[t]{3}{*}{ rs17861118 } & Imputed & 15 & $8.3 \mathrm{~kb} 5^{\prime}$ of CYP1A1 & PD & $0.49(0.39,0.59)$ & $2.6 \times 10^{-21}$ & $0.1(-0.12,0.33)$ & $3.8 \times 10^{-01}$ & $-0.23(-1.81,1.35)$ & $7.8 \times 10^{-01}$ & 0.001 \\
\hline & & & & $\mathrm{DA}$ & $0.66(0.52,0.79)$ & $3.4 \times 10^{-22}$ & $0.09(-0.21,0.39)$ & $5.6 \times 10^{-01}$ & $-0.02(-2.11,2.08)$ & $9.9 \times 10^{-01}$ & 0.0006 \\
\hline & & & & NDA & $-0.34(-0.49,-0.19)$ & $5.0 \times 10^{-06}$ & $-0.08(-0.41,0.24)$ & $6.1 \times 10^{-01}$ & $-0.18(-2.48,2.13)$ & $8.8 \times 10^{-01}$ & 0.08 \\
\hline
\end{tabular}

${ }^{a}$ Adjusted for study, reference age, case status, former use of menopausal hormone therapy, body mass index, number of pregnancies and principal components. SNP single nucleotide polymorphism, Chr chromosome,

$P D$ percent density $(\%)$, square-root-transformed, $D A$ dense area $\left(\mathrm{cm}^{2}\right)$, square-root-transformed, NDA non-dense area $\left(\mathrm{cm}^{2}\right)$, square-root-transformed 
modifier of breast cancer risk in BRCA2-mutation carriers [48]. The functional role of PLCG2 in breast cancer has to be further elucidated before it is possible to derive a model that would explain our findings with PLCG2 variants.

Two studies reported significant interactions between MHT use and genetic variants in hormone-related genes on mammographic density [24, 28]. The first study of 232 postmenopausal women in clinical trials of estrogen therapy and combined estrogen-progesterone therapy investigated the change in percent mammographic density between a baseline mammogram and a mammogram taken at about one year after randomization [24]. Significant interactions between the assignment to the estrogen therapy/combined estrogen-progesterone therapy treatment arm and the CYP1B1 Val432Leu (rs1056836) polymorphism and the AKR1C4 Leu311Val (rs17134592) polymorphism were reported $\left(P_{\text {int }}=0.0004\right.$ and 0.001 , respectively). The CYP1B1 Val432Leu polymorphism was previously evaluated for interaction with MHT use in 538 women and no interaction for percent mammographic density was found $\left(P_{\text {int }}=0.70\right)$ [22]. In this study, neither the CYP1B1 Val432Leu nor the AKR1C4 Leu311Val polymorphism showed an interaction with current use of MHT on percent mammographic density ( $P_{\text {int }}=0.19$ and 0.47 , respectively). The second and larger study of 2,036 postmenopausal women who attended the Norwegian Breast Cancer Screening Program reported a significant interaction between SNP rs10946545 located $1.4 \mathrm{~kb} 3^{\prime}$ of $P R L$ and current use of estrogenprogesterone therapy for percent mammographic density $\left(P_{\text {int }}=0.0008\right)$ [28]. This SNP did not show a potential interaction with current MHT use here $\left(P_{\text {int }}=0.07\right)$, however, the non-significant interaction was in the same direction as that previously reported [28]. Several other variants located in the $5^{\prime}$ region of $P R L$ had the lowest $P_{\text {int }}$ values (Table 3 ), however, they were not in LD with rs10946545. The function of those SNPs near PRL is unknown, the SNP with the strongest interaction (rs9358531) is not located in an obvious regulatory element (Additional file 10: Figure S2). PRL encoding the hormone prolactin may be an interesting candidate for further studies of interactions between genetic variants and use of MHT with respect to mammographic density. In humans, prolactin is primarily produced in the anterior pituitary gland, but it is also expressed in the mammary gland itself and adipose tissue, among others [49]. In postmenopausal women, higher prolactin levels have been associated with higher mammographic density in three studies [50-52], two other studies found no association $[53,54]$.

Ten loci have been identified by GWAS to be associated with percent mammographic density, ZNF365-rs10995190 [10, 30], 12q24-rs1265507 [31], and AREG-rs10034692,
PRDM6-rs186749, ESR1-rs12665607, 8p11.23-rs7816345, LSP1-rs3817198, IGF1-rs703556, TMEM184B-rs7289126, and SGSM3-rs17001868 [10]. The ZNF365, ESR1, LSP1 and SGSM3 loci are also associated with breast cancer risk $[10,30]$, implicating a shared genetic basis of mammographic density and breast cancer. This is also supported by the findings of a study, which assessed a polygenic score based on mammographic density GWAS with respect to breast cancer risk [8]. Women in the top $10 \%$ of the score had an associated $31 \%$ increased risk of breast cancer compared to women in the bottom $10 \%$ of the score. The locus on 12q24 on the other hand, seems not to be associated with breast cancer risk [31]. Our data indicated that associations of the SNPs identified by GWAS with mammographic density are unlikely to be modified by MHT use.

Unlike in previous studies investigating interactions between genetic variants and MHT use with regard to mammographic density, the comprehensive set of SNPs investigated here was not only based on candidate genes, but selected also based on genome-wide case-only geneenvironment interaction studies on breast cancer risk. GWAS have been generally more successful at identifying novel associations with complex diseases than candidate gene or linkage studies [55]. Thus, this approach to selecting SNPs can be considered as more promising. On the other hand, in doing so we made the fairly strong assumption that the biological mechanisms involved in the increase in breast cancer risk associated with MHT use at least in part overlap with the mechanisms involved in the increase in mammographic density associated with MHT use. This does not necessarily have to be true, although we identified polymorphisms in PLCG2 that had interactions with MHT use for both breast cancer risk and mammographic density.

We were able to account for potential confounders of the association between current use of MHT and mammographic density such as age, BMI, case status, and number of pregnancies. All included studies were genotyped using the same genotyping platform. The study design and methods used to measure mammographic density varied between studies included in this analysis. However, the estimates for association and interaction were consistent across studies, supporting the robustness of our results. The sample size of our study was fairly large and the power was sufficient to detect strong SNP-MHT interactions on mammographic density with a beta value of 0.40 . However, the power to detect weak to moderate interactions, in the range we observed in this dataset with betas of about 0.20 , was limited and would require a sample at least four times larger. It is therefore possible that we missed potentially relevant interactions. Another limitation is the lack of type-specific information on MHT use. We could therefore not 
investigate interactions with use of combined estrogenprogesterone therapies, which seem to be more strongly associated with an increased mammographic density than estrogen-only therapies $[16,17]$. Studies with typespecific information on MHT use could therefore also observe interactions of larger magnitudes compared to the magnitudes of the interactions observed here. However, the four genome-wide gene-environment interaction studies on which we partly based our SNP selection also investigated solely interactions with use of any MHT.

\section{Conclusion}

We observed little evidence for strong interactions between the investigated SNPs and MHT use on mammographic density. The study identified variants near $P R L$ and also in PLCG2 for cases only, as potential modifiers of the association between MHT use and mammographic density. These findings will need to be confirmed in larger independent studies. The identification of additional gene-MHT interactions is likely to require very large (genome-wide) studies with type-specific information on MHT use, given the likely moderate/weak magnitude of such interactions.

\section{Additional files}

Additional file 1: Table S1. Description of studies. (DOC $84 \mathrm{~kb}$ )

Additional file 2: Table S2. Selected characteristics of the study population by study. ABCFS Australian breast cancer family study, BBCC Bavarian breast cancer cases and controls, MCBS Mayo clinic breast cancer study, MCCS Melbourne collaborative cohort study, MEC Multi-ethnic cohort, MMHS Mayo mammography health study, OFBCR Ontario familial breast cancer registry, SASBAC Singapore and Sweden breast cancer study, EPIC European prospective investigation into cancer and nutrition, SIBS Sisters in breast screening study. (DOC $87 \mathrm{~kb}$ )

Additional file 3: Table S3. Ten single nucleotide polymorphisms (SNPS) showing lowest $P$ values for interaction with current use of menopausal hormone therapy (MHT) on percent mammographic density. Chr chromosome. (DOC 48 kb)

Additional file 4: Table S6. a Beta estimates for interaction between single nucleotide polymorphisms (SNPS) and use of hormone replacement therapy (MHT) on percent density and for association between SNP and percent density. $\mathbf{b}$ beta estimates for interaction between SNPs and use of MHT on dense area $\left(\mathrm{cm}^{2}\right)$ and for association between SNPs and dense area $\left(\mathrm{cm}^{2}\right)$. $\mathbf{c}$ beta estimates for interaction between SNPs and use of MHT on non-dense area $\left(\mathrm{cm}^{2}\right)$ and for association between SNPs and non-dense area $\left(\mathrm{cm}^{2}\right)$. (ZIP $\left.2747 \mathrm{~kb}\right)$

Additional file 5: Table S4. Beta estimates and confidence intervals for interaction between selected single nucleotide polymorphisms (SNPS) and current menopausal hormone therapy (MHT) use on square-root-transformed percent mammographic density. (DOC 65 kb)

Additional file 6: Table S5. Beta estimates for interactions between selected single nucleotide polymorphisms (SNPS) in PLCG2 and current use of menopausal hormone therapy (MHT) on square-root-transformed percent mammographic density in women not diagnosed with breast cancer and in women with breast cancer. Chr chromosome. (DOC 37 kb)

Additional file 7: Table S7. Estimates for association between single nucleotide polymorphisms (SNPS) identified in genome-wide association studies (GWAS) and percent density, dense area and non-dense area. Chr chromosome. (DOC $46 \mathrm{~kb}$ )
Additional file 8: Table S8. Estimates for interaction between use of menopausal hormone therapy and single nucleotide polymorphisms (SNPS) identified in genome-wide association studies (GWAS) for percent density, dense area and non-dense area. Chr chromosome. (DOC 46 kb)

Additional file 9: Figure S1. University of California Santa Cruz (UCSC) Genome browser view (chr16:81958200-81963700) showing the intergenic position of single nucleotide polymorphisms (SNPS) rs7192724, rs17202296, and rs4888190, and correlated SNPs (r2>0.6 in 1000 Genomes CEU Pilot population). (DOC $231 \mathrm{~kb}$ )

Additional file 10: Figure S2. University of California Santa Cruz (UCSC) Genome browser view (chr6:22308200-22348900) showing the position of single nucleotide polymorphisms (SNPs) rs9356811, rs10946546, rs9358531, rs9393273, rs12525289, rs12199382 and rs12524161. (DOC 261 kb)

\section{Abbreviations}

ABCFS: Australian breast cancer family study; BBCC: Bavarian breast cancer cases and controls; BCAC: Breast Cancer Association Consortium; BMI: body mass index; chr: chromosome; Cl: confidence interval; EPIC: European prospective investigation into cancer and nutrition; FDR: false discovery rate; GWAS: genome-wide association studies; iCOGS: custom Illumina iSelect genotyping array; LD: linkage disequilibrium; MAF: MCBS, Mayo clinic breast cancer study; MCCS: Melbourne collaborative cohort study; MEC: Multi-ethnic cohort, minor allele frequency; MHT: menopausal hormone therapy; MMHS: Mayo mammography health study; OFBCR: Ontario familial breast cancer registry; $P_{\text {int: }} P$-value for interaction; SASBAC: Singapore and Sweden breast cancer study; SIBS: Sisters in breast screening study; SNP: single nucleotide polymorphism; UCSC: University of California Santa Cruz.

\section{Competing interests}

The authors have declared that they have no competing interests.

\section{Authors' contributions}

JCC, AR, CV, and IdSS conceived and designed the study. PAF, MKB, QW, DT, $K C, J S B, J L, C S, V S P, K B, E H, J E O, A L, M W B, A B E, L H, G M, L L M, F S, R L M, J A K$, CA, MCS, MKK, JLH, ILA, GGG, CAH, KTK, RLM, PH, PDPP, FJC, DFE, IDSS, CV, and JCC performed acquisition of data. SB and UE helped analyze the data. AR analyzed the data, interpreted results and drafted the manuscript. JCC, $\mathrm{CV}$, IdSS, and DT reviewed and helped draft the manuscript. All authors have been involved in revising the manuscript critically for important intellectual content and read and approved the final manuscript.

\section{Acknowledgements}

Names of the approving ethical committees are as follows: ABCFS, The University of Melbourne and The Cancer Councils of Victoria and New South Wales; BBCC, Ethics Committee of the Friedrich-Alexander-University Erlangen-Nuremberg; EPIC: Norwich Local Research Ethics Committee; MCBCS, Mayo Institutional Review Board; MCCS, The Cancer Council Victoria's Human Research Ethics Committee; MEC, Institutional Review Boards of the University of Hawaii and University of Southern California; MMHS, Mayo Institutional Review Board; OFBCR, Mount Sinai Hospital Research Ethics Board; SASBAC, Regionala Etikprovningsnamnden i Stockholm (Regional Ethical Review Board in Stockholm); SIBS, Eastern Multicentre Research Ethics Committee; BCAC/COGS, this study would not have been possible without the contributions of the following: Andrew Lee, and Ed Dicks, Craig Luccarini and the staff of the Centre for Genetic Epidemiology Laboratory, Javier Benitez, Anna Gonzalez-Neira and the staff of the CNIO genotyping unit, Jacques Simard and Daniel C. Tessier, Francois Bacot, Daniel Vincent, Sylvie LaBoissière and Frederic Robidoux and the staff of the McGill University and Génome Québec Innovation Centre, Stig E. Bojesen, Sune F. Nielsen, Borge G. Nordestgaard, and the staff of the Copenhagen DNA laboratory, and Julie M. Cunningham, Sharon A. Windebank, Christopher A. Hilker, Jeffrey Meyer and the staff of Mayo Clinic Genotyping Core Facility. Funding for the iCOGS infrastructure came from: the European Community's Seventh Framework Programme under grant agreement $n^{\circ} 223175$ (HEALTH-F2-2009-223175) (COGS), Cancer Research UK (C1287/A10118, C1287/A 10710, C12292/A11174, C1281/A12014, C5047) A8384, C5047/A15007, C5047/A10692, C8197/A16565), the National Institutes of Health (CA128978) and Post-Cancer GWAS initiative (1U19 CA148537, 1 U19 CA148065 and 1 U19 CA148112 - the GAME-ON initiative), the Department of Defence (W81XWH-10-1-0341), the Canadian Institutes of Health Research (CIHR) for the CIHR Team in Familial Risks of Breast Cancer, Komen Foundation for the 
Cure, the Breast Cancer Research Foundation, and the Ovarian Cancer Research Fund. ABCFS would like to thank Maggie Angelakos, Judi Maskiell, and Gillian Dite. The ABCFS was supported by grant UM1 CA164920 from the National Cancer Institute (USA). The content of this manuscript does not necessarily reflect the views or policies of the National Cancer Institute or any of the collaborating centers in the Breast Cancer Family Registry (BCFR), nor does mention of trade names, commercial products, or organizations imply endorsement by the USA Government or the BCFR. The ABCFS was also supported by the National Health and Medical Research Council of Australia, the New South Wales Cancer Council, the Victorian Health Promotion Foundation (Australia) and the Victorian Breast Cancer Research Consortium. JLH is a National Health and Medical Research Council (NHMRC) Australia Fellow and a Victorian Breast Cancer Research Consortium Group Leader. MCS is a NHMRC Senior Research Fellow and a Victorian Breast Cancer Research Consortium Group Leader. The work of the BBCC was partly funded by ELAN-Fond of the University Hospital of Erlangen. EPIC-Norfolk was funded by research program grant funding from Cancer Research UK and the Medical Research Council with additional support from the Stroke Association, British Heart Foundation, Department of Health, Research into Ageing and Academy of Medical Sciences. The MCBCS was supported by the NIH grants CA128978, CA116167, CA176785 an NIH Specialized Program of Research Excellence (SPORE) in Breast Cancer [CA116201], and the Breast Cancer Research Foundation and a generous gift from the David F. and Margaret T. Grohne Family Foundation and the Ting Tsung and Wei Fong Chao Foundation. MCCS cohort recruitment was funded by VicHealth and Cancer Council Victoria. The MCCS was further supported by Australian NHMRC grants 209057, 251553 and 504711 and by infrastructure provided by Cancer Council Victoria. The MEC was supported by NIH grants CA63464, CA54281, CA098758 and CA132839. MMHS would like to acknowledge the participants within the Mayo Mammography Health Study, Ms. Fang Fang Wu for her review of all mammograms for the study and the Array Corporation, USA, for the donation of the digitizer that enabled this work. The MMHS work was supported by the National Cancer Institute within the National Institutes of Health (R01 CA128931, R01 CA140286, R01 CA97396, P50 CA116201, R01 CA177150). The Ontario Familial Breast Cancer Registry (OFBCR) was supported by grant UM1 CA164920 from the National Cancer Institute (USA). The content of this manuscript does not necessarily reflect the views or policies of the National Cancer Institute or any of the collaborating centers in the Breast Cancer Family Registry (BCFR), nor does mention of trade names, commercial products, or organizations imply endorsement by the USA Government or the BCFR. SASBAC thanks the Swedish Medical Research Counsel. SASBAC study was supported by funding from the Agency for Science, Technology and Research of Singapore (A*STAR), the US National Institute of Health $(\mathrm{NIH})$ and the Susan $\mathrm{G}$. Komen Breast Cancer Foundation. The SIBS study was supported by program grant C1287/A10118 and project grants from Cancer Research UK (grant numbers C1287/8459).

\section{Author details}

'Division of Cancer Epidemiology, German Cancer Research Center (DKFZ), Im Neuenheimer Feld 581, D-69120 Heidelberg, Germany ${ }^{2}$ Department of Gynaecology and Obstetrics, University Hospital Erlangen, Friedrich-Alexander University Erlangen-Nuremberg, Comprehensive Cancer Center Erlangen-EMN, Erlangen, Germany. ${ }^{3}$ David Geffen School of Medicine, Department of Medicine Division of Hematology and Oncology, University of California at Los Angeles, Los Angeles, CA, USA. ${ }^{4}$ Centre for Cancer Genetic Epidemiology, Department of Public Health and Primary Care, University of Cambridge, Cambridge, UK. ${ }^{5}$ Department of Medical Epidemiology and Biostatistics, Karolinska Institutet, Stockholm, Sweden. 'Division of Biostatistics, Mayo Clinic, Rochester, MN, USA. ${ }^{7}$ Department of Radiology, Mayo Clinic, Rochester, MN, USA. ${ }^{8}$ Department of Health Sciences Research, Mayo Clinic, Rochester, MN, USA. ${ }^{9}$ Department of Molecular Pharmacology and Experimental Therapeutics, Mayo Clinic, Rochester, MN, USA. ${ }^{19}$ Institute of Human Genetics, University Hospital Erlangen, Friedrich-Alexander University Erlangen-Nuremberg, Comprehensive Cancer Center Erlangen-EMN, Erlangen, Germany. ${ }^{11}$ University of Hawaii Cancer Center, Honolulu, HI, USA. ${ }^{12}$ Department of Preventive Medicine, Keck School of Medicine, University of Southern California, Los Angeles, CA, USA. ${ }^{13}$ Cancer Epidemiology Centre, Cancer Council Victoria, Melbourne, Australia. ${ }^{14}$ Centre for Epidemiology and Biostatistics, Melbourne School of Population and Global Health, The University of Melbourne, Melbourne, Australia. ${ }^{15}$ Prosserman Centre for Health Research, Lunenfeld-Tanenbaum Research Institute of Mount Sinai Hospital, Toronto, Canada. ${ }^{16}$ Division of Epidemiology, Dalla Lana School of
Public Health, University of Toronto, Toronto, Canada. ${ }^{17}$ Department of Pathology, The University of Melbourne, Melbourne, Australia.

${ }^{18}$ Lunenfeld-Tanenbaum Research Institute of Mount Sinai Hospital, Toronto, Canada. ${ }^{19}$ Department of Molecular Genetics, University of Toronto, Toronto, Canada. ${ }^{20}$ MRC Centre for Nutritional Epidemiology in Cancer Prevention and Survival (CNC), University of Cambridge, Cambridge, UK. ${ }^{21}$ Clinical Gerontology, Department of Public Health and Primary Care, University of Cambridge, Cambridge, UK. ${ }^{22}$ Centre for Cancer Genetic Epidemiology, Department of Oncology, University of Cambridge, Cambridge, UK. ${ }^{23}$ Department of Laboratory Medicine and Pathology, Mayo Clinic, Rochester, MN, USA. ${ }^{24}$ Department of Non-Communicable Disease Epidemiology, London School of Hygiene and Tropical Medicine, London, UK.

Received: 13 May 2015 Accepted: 29 July 2015

\section{Published online: 16 August 2015}

\section{References}

1. McCormack VA, dos Santos SI. Breast density and parenchymal patterns as markers of breast cancer risk: a meta-analysis. Cancer Epidemiol Biomarkers Prev. 2006;15:1159-69.

2. Antoni S, Sasco AJ, dos Santos SI, McCormack V. Is mammographic density differentially associated with breast cancer according to receptor status? A meta-analysis. Breast Cancer Res Treat. 2013;137:337-47.

3. Checka CM, Chun JE, Schnabel FR, Lee J, Toth $\mathrm{H}$. The relationship of mammographic density and age: implications for breast cancer screening. AJR Am J Roentgenol. 2012;198:W292-5.

4. Boyd NF, Rommens JM, Vogt K, Lee V, Hopper JL, Yaffe MJ, et al. Mammographic breast density as an intermediate phenotype for breast cancer. Lancet Oncol. 2005;6:798-808.

5. Boyd NF, Martin LJ, Yaffe MJ, Minkin S. Mammographic density and breast cancer risk: current understanding and future prospects. Breast Cancer Res. 2011;13:223.

6. Boyd NF, Martin LJ, Rommens JM, Paterson AD, Minkin S, Yaffe MJ, et al. Mammographic density: a heritable risk factor for breast cancer. Methods Mol Biol. 2009;472:343-60.

7. Brand JS, Humphreys K, Thompson DJ, Li J, Eriksson M, Hall P, et al. Volumetric mammographic density: heritability and association with breast cancer susceptibility loci. J Natl Cancer Inst. 2014;106:12.

8. Varghese JS, Thompson DJ, Michailidou K, Lindstrom S, Turnbull C, Brown J, et al. Mammographic breast density and breast cancer: evidence of a shared genetic basis. Cancer Res. 2012;72:1478-84.

9. Vachon CM, Scott CG, Fasching PA, Hall P, Tamimi RM, Li J, et al. Common breast cancer susceptibility variants in LSP1 and RAD51L1 are associated with mammographic density measures that predict breast cancer risk. Cancer Epidemiol Biomarkers Prev. 2012;21:1156-66.

10. Lindstrom S, Thompson DJ, Paterson AD, Li J, Gierach GL, Scott C, et al. Genome-wide association study identifies multiple loci associated with both mammographic density and breast cancer risk. Nat Commun. 2014:5:5303.

11. Stone J, Thompson DJ, Dos Santos SI, Scott C, Tamimi RM, Lindstrom S, et al. Novel associations between common breast cancer susceptibility variants and risk-predicting mammographic density measures. Cancer Res. 2015;75:2457-67.

12. Brisson J, Brisson B, Cote G, Maunsell E, Berube S, Robert J. Tamoxifen and mammographic breast densities. Cancer Epidemiol Biomarkers Prev. 2000;9:911-5.

13. Chow CK, Venzon D, Jones EC, Premkumar A, O'Shaughnessy J, Zujewski J. Effect of tamoxifen on mammographic density. Cancer Epidemiol Biomarkers Prev. 2000;9:917-21.

14. Cuzick J, Warwick J, Pinney E, Warren RM, Duffy SW. Tamoxifen and breast density in women at increased risk of breast cancer. J Natl Cancer Inst. 2004;96:621-8.

15. Greendale GA, Reboussin BA, Slone S, Wasilauskas C, Pike MC, Ursin G. Postmenopausal hormone therapy and change in mammographic density. J Natl Cancer Inst. 2003;95:30-7

16. McTiernan A, Chlebowski RT, Martin C, Peck JD, Aragaki A, Pisano ED, et al. Conjugated equine estrogen influence on mammographic density in postmenopausal women in a substudy of the women's health initiative randomized trial. J Clin Oncol. 2009;27:6135-43.

17. McTiernan A, Martin CF, Peck JD, Aragaki AK, Chlebowski RT, Pisano ED, et al. Estrogen-plus-progestin use and mammographic density in 
postmenopausal women: Women's Health Initiative randomized trial. J Natl Cancer Inst. 2005;97:1366-76.

18. Martin LJ, Boyd NF. Mammographic density. Potential mechanisms of breast cancer risk associated with mammographic density: hypotheses based on epidemiological evidence. Breast Cancer Res. 2008;10:201

19. Chlebowski RT, Anderson GL. Changing concepts: menopausal hormone therapy and breast cancer. J Natl Cancer Inst. 2012;104:517-27.

20. Spraque BL, Trentham-Dietz A, Cronin KA. A sustained decline in postmenopausal hormone use results from the National Health and Nutrition Examination Survey, 1999-2010. Obstet Gynecol. 2012;120:595-603.

21. Ameye L, Antoine C, Paesmans M, de Azambuja E, Rozenberg S. Menopausal hormone therapy use in 17 European countries during the last decade. Maturitas. 2014;79:287-91.

22. Haiman CA, Hankinson SE, De Vivo I, Guillemette C, Ishibe N, Hunter DJ, et al. Polymorphisms in steroid hormone pathway genes and mammographic density. Breast Cancer Res Treat. 2003:77:27-36.

23. Lillie EO, Bernstein L, Ingles SA, Gauderman WJ, Rivas GE, Gagalang V, et al. Polymorphism in the androgen receptor and mammographic density in women taking and not taking estrogen and progestin therapy. Cancer Res. 2004;64:1237-41

24. Lord SJ, Mack WJ, Van Den Berg D, Pike MC, Ingles SA, Haiman CA, et al. Polymorphisms in genes involved in estrogen and progesterone metabolism and mammographic density changes in women randomized to postmenopausal hormone therapy: results from a pilot study. Breast Cancer Res. 2005:7:R336-44.

25. van Duijnhoven FJ, Peeters PH, Warren RM, Bingham SA, Uitterlinden AG, van Noord PA, et al. Influence of estrogen receptor alpha and progesterone receptor polymorphisms on the effects of hormone therapy on mammographic density. Cancer Epidemiol Biomarkers Prev. 2006;15:462-7.

26. Takata Y, Maskarinec $G$, Le Marchand L. Breast density and polymorphisms in genes coding for CYP1A2 and COMT: the Multiethnic Cohort. BMC Cancer. 2007;7:30.

27. Lee E, Ingles SA, Van Den Berg D, Wang W, Lavallee C, Huang MH, et al. Progestogen levels, progesterone receptor gene polymorphisms, and mammographic density changes: results from the Postmenopausal Estrogen/Progestin Interventions Mammographic Density Study. Menopause. 2012;19:302-10.

28. Ellingjord-Dale M, Lee $\mathrm{E}_{\text {, Couto }}$, Ozhand $\mathrm{A}$, Qureshi $\mathrm{SA}$, Hofvind $\mathrm{S}$, et al. Polymorphisms in hormone metabolism and growth factor genes and mammographic density in Norwegian postmenopausal hormone therapy users and non-users. Breast Cancer Res. 2012;14:R135.

29. Rudolph A, Hein R, Lindstrom S, Beckmann L, Behrens S, Liu J, et al. Genetic modifiers of menopausal hormone replacement therapy and breast cancer risk: a genome-wide interaction study. Endocr Relat Cancer. 2013;20:875-87.

30. Lindstrom S, Vachon CM, Li J, Varghese J, Thompson D, Warren R, et al. Common variants in ZNF365 are associated with both mammographic density and breast cancer risk. Nat Genet. 2011:43:185-7.

31. Stevens KN, Lindstrom S, Scott CG, Thompson D, Sellers TA, Wang X, et al. Identification of a novel percent mammographic density locus at 12q24. Hum Mol Genet. 2012;21:3299-305.

32. Website of the Breast Cancer Association Consortium (BCAC). http:// ccge.medschl.cam.ac.uk/consortia/bcac/index.html

33. Lesueur F, Pharoah PD, Laing S, Ahmed S, Jordan C, Smith PL, et al. Allelic association of the human homologue of the mouse modifier Ptprj with breast cancer. Hum Mol Genet. 2005;14:2349-56.

34. Byng JW, Boyd NF, Fishell E, Jong RA, Yaffe MJ. The quantitative-analysis of mammographic densities. Phys Med Biol. 1994;39:1629-38.

35. Ursin G, Ma HY, Wu AH, Bernstein L, Salane M, Parisky YR, et al. Mammographic density and breast cancer in three ethnic groups. Cancer Epidemiol Biomarkers Prev. 2003;12:332-8.

36. Gram IT, Bremnes Y, Ursin G, Maskarinec G, Bjurstam N, Lund E. Percentage density, Wolfe's and Tabar's mammographic patterns: agreement and association with risk factors for breast cancer. Breast Cancer Res. 2005;7:R854-61

37. Michailidou K, Hall P, Gonzalez-Neira A, Ghoussaini M, Dennis J, Milne RL, et al. Large-scale genotyping identifies 41 new loci associated with breast cancer risk. Nat Genet. 2013;45:353-61.

38. Delaneau O, Zagury JF, Marchini J. Improved whole-chromosome phasing for disease and population genetic studies. Nat Methods. 2013;10:5-6.
39. Howie B, Fuchsberger C, Stephens M, Marchini J, Abecasis GR. Fast and accurate genotype imputation in genome-wide association studies through pre-phasing. Nat Genet. 2012:44:955-9.

40. Michailidou K, Beesley J, Lindstrom S, Canisius S, Dennis J, Lush MJ, et al. Genome-wide association analysis of more than 120,000 individuals identifies 15 new susceptibility loci for breast cancer. Nat Genet. 2015;47:373-80

41. Benjamini $Y$, Hochberg $Y$. Controlling the false discovery rate - a practical and powerful approach to multiple testing. J R Stat Soc Series B Stat Methodol. 1995;57:289-300.

42. Ward LD, Kellis M. HaploReg: a resource for exploring chromatin states, conservation, and regulatory motif alterations within sets of genetically linked variants. Nucleic Acids Res. 2012:40:D930-4.

43. Meyer LR, Zweig AS, Hinrichs AS, Karolchik D, Kuhn RM, Wong M, et al. The UCSC Genome Browser database: extensions and updates 2013. Nucleic Acids Res. 2013;41:D64-9.

44. Wang D, Feng J, Wen R, Marine JC, Sangster MY, Parganas E, et al Phospholipase Cgamma2 is essential in the functions of $B$ cell and several Fc receptors. Immunity. 2000;13:25-35.

45. Tassi I, Presti R, Kim S, Yokoyama WM, Gilfillan S, Colonna M. Phospholipase C-gamma 2 is a critical signaling mediator for murine NK cell activating receptors. J Immunol. 2005;175:749-54.

46. Zhou Q, Lee GS, Brady J, Datta S, Katan M, Sheikh A, et al. A hypermorphic missense mutation in PLCG2, encoding phospholipase Cgamma2, causes a dominantly inherited autoinflammatory disease with immunodeficiency. Am J Hum Genet. 2012;91:713-20.

47. Ombrello MJ, Remmers EF, Sun G, Freeman AF, Datta S, Torabi-Parizi P, et al. Cold urticaria, immunodeficiency, and autoimmunity related to PLCG2 deletions. N Engl J Med. 2012;366:330-8.

48. Walker LC. Waddell N, Ten Haaf A, kConFab I, Grimmond S, Spurdle AB. Use of expression data and the CGEMS genome-wide breast cancer association study to identify genes that may modify risk in BRCA1/2 mutation carriers. Breast Cancer Res Treat. 2008;112:229-36.

49. Marano RJ, Ben-Jonathan N. Minireview: Extrapituitary prolactin: an update on the distribution, regulation, and functions. Mol Endocrinol. 2014;28:622-33

50. Boyd NF, Stone J, Martin LJ, Jong R, Fishell E, Yaffe M, et al. The association of breast mitogens with mammographic densities. Br J Cancer. 2002;87:876-82.

51. Greendale GA, Huang MH, Ursin G, Ingles S, Stanczyk F, Crandall C, et al. Serum prolactin levels are positively associated with mammographic density in postmenopausal women. Breast Cancer Res Treat. 2007;105:337-46.

52. Rice MS, Tworoger SS, Bertrand KA, Hankinson SE, Rosner BA, Feeney YB, et al. Immunoassay and Nb2 lymphoma bioassay prolactin levels and mammographic density in premenopausal and postmenopausal women the Nurses' Health Studies. Breast Cancer Res Treat. 2015;149:245-53.

53. Bremnes Y, Ursin G, Bjurstam N, Rinaldi S, Kaaks R, Gram IT. Endogenous sex hormones, prolactin and mammographic density in postmenopausal Norwegian women. Int J Cancer. 2007;121:2506-11.

54. Maskarinec G, Takata Y, Chen Z, Gram IT, Nagata C, Pagano I, et al. IGF-I and mammographic density in four geographic locations: a pooled analysis. Int J Cancer. 2007;121:1786-92.

55. Manolio TA. Bringing genome-wide association findings into clinical use. Nat Rev Genet. 2013;14:549-58.

\section{Submit your next manuscript to BioMed Central and take full advantage of:}

- Convenient online submission

- Thorough peer review

- No space constraints or color figure charges

- Immediate publication on acceptance

- Inclusion in PubMed, CAS, Scopus and Google Scholar

- Research which is freely available for redistribution 